\title{
Wheezing phenotypes in young children: an historical cohort study
}

\author{
*Alfredo Cano-Garcinuño ${ }^{1}$, Isabel Mora-Gandarillas ${ }^{2}$ and the SLAM Study Group ${ }^{3 \dagger}$ \\ 1 Villamuriel Primary Care Health Centre, Regional Health Service, Castilla y León, Spain \\ ${ }^{2}$ Infiesto Primary Care Health Centre, Regional Health Service, Principado de Asturias, Spain \\ ${ }^{3}$ Primary Care, Regional Health Service, Principado de Asturias, Spain \\ †The SLAM (Sibilancias de Lactante y Asma de Mayor) Study Group are: Ángeles Cobo-Ruisánchez, Ignacio Pérez-Candás, Encarnación Díaz \\ Estrada, Begoña Yáñez-Meana, Águeda García-Merino, Ana Arranz-Velasco, Ignacio Carvajal-Urueña, Begoña Domínguez-Aurrecoechea, \\ Carolina Ruano-Fajardo, María Fernández-Francés, María Luisa García-Balbuena, Ana Pérez-Vaquero, Rosa Buznego-Sánchez, Leonor \\ Merino-Ramos, Luz María Alonso-Bernardo, Mar Coto-Fuente, Milagros Moreno-Sierra, Rosa Rodríguez-Posada, Fernando Nuño-Martín, \\ Francisco Fernández-López, María Ángeles Ordóñez-Alonso, Agustina Alonso-Álvarez, María García-Adaro, Luís Miguel Fernández-Cuesta, \\ Zoa García-Amorín, Felipe González-Rodríguez, Aidé Aladro-Antuña, Isabel Carballo-Castillo, Carmen Castañón-Rodríguez, \\ Ángel Costales-Álvarez
}

Received 7th August 2013; revised 2nd November 2013; accepted 30th December 2013; online 20th February 2014

\begin{abstract}
Background: Wheezing phenotypes in young children have usually been described on the basis of questionnaire surveys instead of prospectively doctor-diagnosed episodes, and have never been described in terms of incidence rates.

Aims: To identify wheezing phenotypes in the first three years and describe their incidence trends, and to investigate their relationship with asthma at six years of age.

Methods: Doctor-diagnosed wheezing episodes in the first 36 months and active asthma at six years were identified in a historical cohort of 3,739 children followed from birth in 29 primary care health centres in Spain. Wheezing phenotypes were identified by means of latent class analysis. Changes in incidence rates of wheezing were identified through joinpoint regression models and their predictive ability for asthma was analysed.

Results: One never/infrequent wheeze phenotype and three wheezing phenotypes were identified. There were two early phenotypes which started wheezing at a median age of six months, one of which was transient while the other had a heavy recurrence of episodes. A third phenotype exhibited a delayed onset of wheezing, a constant rise in incidence through the first 36 months, and a relationship with allergic asthma. These three phenotypes had a higher prevalence of active asthma at six years than the never/infrequent wheeze phenotype, but the classification had a weak predictive ability for asthma due to low sensitivity.

Conclusions: The use of incidence rates contributes to the clarification of the natural history of infant wheezing.

(C) 2014 Primary Care Respiratory Society UK. All rights reserved.

A Cano-Garcinuño et al. Prim Care Respir J 2014; 23(1): 60-66

http://dx.doi.org/10.4104/pcrj.2014.00008
\end{abstract}

Keywords cohort studies, asthma, infant, child, respiratory sounds

See linked editorial by Brand on pg 10

The full version of this paper, with online appendices,

is available online at www.thepcrj.org

\section{Introduction}

Wheezing often occurs in infants with respiratory diseases. It is usually related to viral respiratory infections, although some children also wheeze in response to other triggers and have symptoms between episodes.' The age of onset and the recurrence of wheezing have been used as the basis for imprecise nomenclatures of these episodes, which get many diagnostic labels with therapeutic consequences. ${ }^{2}$ Wheeze is also a manifestation of asthma, and there is concern about the relationship between wheezing in young

\footnotetext{
* Corresponding author: Dr Alfredo Cano-Garcinuño, Centro de Salud, Avenida Valdegudín sn. Villamuriel de Cerrato, Palencia 34190, Spain. Tel: +34 979776301 E-mail: acanog@saludcastillayleon.es
} 
children and later asthma.

The natural history of wheezing in young children has been studied, and searches have been made for phenotypes that associate different prognoses and risk factors. A pioneer study in this field was the Tucson Children's Respiratory Study which classified infant wheezing in the first three years as either transient or persistent, depending on the absence or presence of symptoms at six years of age. ${ }^{3}$ Although the same procedure has been used in other studies, ${ }^{4,5}$ this is not the best way to classify infant wheezing as these categories are a priori created by the researcher and their existence depends only on the occurrence of asthma symptoms in the school years. A high diversity of infant wheezing could be masked in this classification.

To avoid these problems, probabilistic classification methods such as latent class analysis ${ }^{6}$ (LCA) have been used in recent studies. ${ }^{7-10}$ LCA has highlighted a more complex reality in infant wheezing and has shown that a number of wheezing phenotypes can be identified before three or four years of age. These studies have improved our knowledge of the natural history of wheezing in young infants, but they have limitations. They analysed parents' answers to questionnaires completed at scheduled ages, asking for events that happened during a previous period. This information is retrospective and subjective, it does not fit clinical criteria, and it incorrectly estimates the true incidence of wheezing." $\mathrm{A}$ validation of the results of these studies against prospective doctor-diagnosed wheezing is lacking. Moreover, a description of phenotypes in terms of incidence rates of wheezing episodes has never been done. Such a description is essential for understanding the meaning of the phenotype classification, as it would show the disease burden for each phenotype and the age at which the incidence peaks or subsides.

The present study aimed to identify time patterns and phenotypes of doctor-diagnosed wheezing in the first 36 months of life, to describe the changes in incidence rates of wheezing episodes in those phenotypes, and to analyse their relationship with active asthma at six years of age.

\section{Methods}

\section{Population and setting}

The SLAM (Sibilancias de Lactante y Asma de Mayor) study used data from a historical cohort composed of all six-year-old children born between 2002 and 2004 in a population covered by 29 primary healthcare practices in Asturias, a northern Spanish region with a high prevalence of asthma. Children were assigned at birth to a primary healthcare centre where a paediatrician acted as the primary care physician for children under 14 years of age. All children attended a scheduled visit at six years, when a review of health problems, vaccination, and other preventive care was provided by the attending paediatrician.

Children with specific diseases related to chronic or recurrent respiratory problems were not included (see Appendix 1 available online at www.thepcrj.org). Incomplete follow-up was noted if a child did not have a complete clinical record because he or she was not assigned to the study centre at birth. These were children who had either changed residency or been born abroad.

\section{Information about wheeze and asthma}

Clinical records were reviewed for wheezing episodes in the first 36 months of life. The review included both paper and electronic clinical records (since 2001 all primary healthcare practices in Asturias have used the same electronic clinical recording system), as well as reports of both hospitalisations and emergency room visits, which are routinely documented in clinical records.

A wheezing episode was defined as any respiratory disease in which a physician recorded that wheeze was auscultated on physical examination. One month was required as a minimum elapsed time between distinct episodes. Clinical records were also used to identify active asthma at six years, defined as the occurrence in the previous 12 months of both symptoms attributed to asthma by a paediatrician and the receipt of at least one anti-asthma drug prescription.

Results of allergy tests for airborne allergens (either skin prick tests or serum-specific immunoglobulin $\mathrm{E}$ determinations) were identified in the clinical records of children with asthma. The type and number of tested allergens could vary according to clinical needs, but dust mite sensitisation was always included for testing because it is the allergen most commonly associated with asthma in Asturias. When results of allergy tests were available, asthma was classified as either allergic or non-allergic on the basis of a positive or negative test to any airborne allergen.

\section{Analysis of data}

Data analysis was conducted in three steps. First, LCA was applied to identify phenotypes of wheezing. Latent-class cluster models were built with 12 nominal variables that represented the occurrence or absence of any wheezing episode in each threemonth period between 0 and 36 months of age. Models with between one and seven classes were investigated, and the best model was selected according to three criteria: lowest Bayesian information criterion (BIC), good fit to the data distribution ( $p>0.05$ in a bootstrap $\mathrm{L}^{2}$ test), and significant fit improvement over a model with one less number of classes ( $p<0.05$ in a conditional bootstrap $2 \mathrm{LL}$ test). Children were classified in the class they most probably belonged to (this is termed modal classification). This modal classification entails an error rate that can be estimated by comparison with the probabilistic distribution of each class. Between-class differences among clusters in a number of characteristics were analysed by $\chi^{2}$ or Kruskal-Wallis statistics as needed, and time to the first wheezing episode was analysed by the Kaplan-Meier survival method.

Second, mean monthly incidence rates of wheezing episodes per 1,000 person-months through the first 36 months were computed for each phenotype identified by LCA, and changes in incidence rates were analysed through joinpoint regression models. This is a least square linear regression method that allows the identification of both trends in incidence rates and points (joinpoints) at which incidence changes. ${ }^{12}$ Linear joinpoint regression models were built with the monthly incidence rate of wheezing as the dependent variable and the midpoint of each monthly period as the independent variable. Homoscedasticity and lack of autocorrelation were assumed and later tested. For each phenotype, 
models with between 0 and 5 joinpoints were built and the best model was chosen by a permutation test with a significance level of p $<0.05$ after a Bonferroni correction for repeated tests. ${ }^{12}$

Third, the modal classification was tested for its ability to predict active asthma at six years of age by computing sensitivity, specificity, and the Brierscaled, a measure of overall predictive performance standardised to give a result between 0 (minimum) and 100 (maximum predictive ability)..$^{13}$

LCA was conducted by means of the Latent Gold 4.5 software (Statistical Innovations, Boston, USA) and joinpoint regression models were built using the Joinpoint Regression Program (US National Cancer Institute). Other analyses were conducted by means of Excel (Microsoft Corporation).

\section{Ethics approval}

The study protocol was approved by the Regional Clinical Research Ethics Committee of the Principado de Asturias (number 03/2011).

\section{Results}

\section{Sample}

Out of a cohort of 4,765 children, $36(0.8 \%)$ had one of the exclusion criteria (Appendix 1 and 4 available online at www.thepcrj.org). There were 990 children (20.8\%) with incomplete follow-up, but no differences were found in sex, year of birth, or birth weight between children with and without complete follow-up. The analysis used the complete data from 3,739 children (51.2\% male).

There were 4,676 recorded wheezing episodes and 1,704
Figure 1. Probability of wheeze in each three-month period from birth to 36 months in the never/infrequent (square marker, bold continuous line), late (circle marker, bold broken line), transient (circle marker, light continuous line), and persistent (square marker, light broken line) wheezing classes

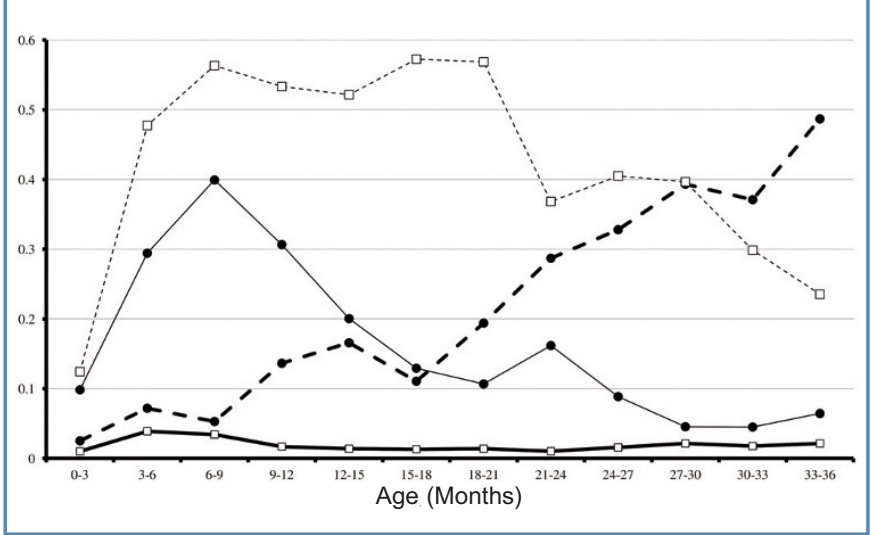

children (45.6\%) had at least one of them. Active asthma at six years of age was identified in 573 children (15.3\%). Wheezing in the first 36 months was more common in children with asthma than in those without asthma (73.6\% versus $40.5 \%, p<0.001)$.

\section{Phenotypes and incidence rates}

A model with four classes was chosen after LCA as it fulfilled the

Table 1. Incidence joinpoint regression models for the classes identified in latent-class analysis

\begin{tabular}{|c|c|c|c|c|c|c|}
\hline IR model & $\mathrm{R}^{2}$ & Parameter & $\begin{array}{l}\text { Parameter } \\
\text { estimate }(95 \% \mathrm{Cl})^{\ddagger}\end{array}$ & $\mathrm{p}$ Value & $\begin{array}{l}\text { Number } \\
\text { of joinpoints }\end{array}$ & $\begin{array}{l}\text { Joinpoint location } \\
(95 \% \mathrm{Cl})^{+}\end{array}$ \\
\hline \multirow{6}{*}{$\begin{array}{l}\text { Never/infrequent } \\
\text { wheeze }\end{array}$} & \multirow[t]{6}{*}{0.906} & Intercept 1 & $-5.91(-9.37$ to -2.45$)$ & 0.003 & \multirow[t]{6}{*}{3} & $6.5(3.5$ to 7.5$)$ \\
\hline & & Intercept 3 & 3.34 (0.29 to 6.38$)$ & 0.042 & & 34.5 (12.5 to 34.5$)$ \\
\hline & & Intercept 4 & $-59.98(-207.46$ to 87.51$)$ & 0.433 & & \\
\hline & & Slope $1 *$ & $3.83(2.92$ to 4.75$)$ & $<0.001$ & & \\
\hline & & Slope $3^{*}$ & $0.10(-0.03$ to 0.22$)$ & 0.134 & & \\
\hline & & Slope $4^{*}$ & $1.93(-2.17$ to 6.03$)$ & 0.364 & & \\
\hline \multirow[t]{3}{*}{ Transient wheeze } & \multirow[t]{3}{*}{0.920} & Intercept 1 & $-37.94(-75.15$ to -0.72$)$ & 0.055 & \multirow[t]{3}{*}{2} & 7.5 (5.5 to 9.5$)$ \\
\hline & & Intercept 2 & 339.37 (271.90 to 406.85$)$ & $<0.001$ & & 16.5 (12.5 to 20.5$)$ \\
\hline & & Intercept 3 & $120.93(82.61$ to 159.25$)$ & $<0.001$ & & \\
\hline \multirow[t]{4}{*}{ Persistent wheeze } & \multirow[t]{4}{*}{0.783} & Intercept 1 & $-111.30(-204.26$ to -18.35$)$ & 0.026 & \multirow[t]{4}{*}{1} & \multirow[t]{4}{*}{$6.5(5.5$ to 8.5$)$} \\
\hline & & Intercept 2 & 337.59 (298.76 to 376.43$)$ & $<0.001$ & & \\
\hline & & Slope $1^{*}$ & 62.60 (37.98 to 87.23$)$ & $<0.001$ & & \\
\hline & & Slope $2^{*}$ & $-6.46(-8.10$ to -4.82$)$ & $<0.001$ & & \\
\hline \multirow[t]{2}{*}{ Late wheeze } & \multirow[t]{2}{*}{0.908} & Intercept 1 & $-28.34(-46.70$ to -9.98$)$ & 0.005 & \multirow[t]{2}{*}{0} & \\
\hline & & Slope $1^{*}$ & $6.56(5.71$ to 7.40$)$ & $<0.001$ & & \\
\hline
\end{tabular}


Figure 2. Joinpoint regression lines: incidence rates per 1,000 person-months for each wheezing class: never/ infrequent wheezing (bold continuous line), late wheezing (bold broken line), transient wheezing (light continuous line), and persistent wheezing (light broken line.

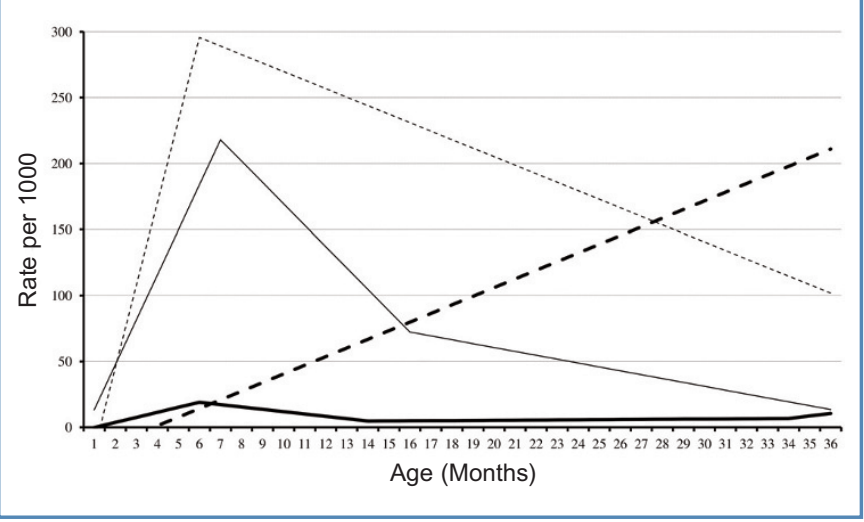

three abovementioned selection criteria (see Appendix 2 available online at www.thepcrj.org). These classes were defined by the probability of having any wheezing episode in each three-month period (Figure 1). Further description of these classes through estimates of monthly incidence rates of wheezing for each class was obtained by means of joinpoint regression models, as shown in Table 1 and Figure 2 (additional data in Appendix 3 available online at www.thepcrj.org). The following four phenotypes could be described:

(1) "Never/infrequent wheeze" (NIW) is a class with a very low incidence of wheezing. All children who never wheezed belonged to this class; only $25.6 \%$ of the class members had any wheezing episode and none had more than three episodes in the first 36 months. They had a little peak of incidence at 6.5 months and then a fall until 14.5 months with later stabilisation (no more significant slopes).

(2) "Transient wheeze" (TW) is a class with a fast rise in the incidence of wheezing from birth to a peak of 218 episodes per 1,000 person-months at 7.5 months, followed by a fast drop in incidence until 16.5 months and subsequently a slower decrease in the incidence rate. The first episode happened at a median (interquartile range, IQR) age of 6 (4-9) months; $90 \%$ of children in this class had their first episode before the 13th month.

(3) "Persistent wheeze" (PW) is a class with a very fast rise in the incidence of wheezing to a peak of 296 episodes per 1,000 person-months at 6.5 months, followed by a slow descent. The first episode occurred at an age of 6 (4-8) months; $90 \%$ of children in this class had their first episode before the 12th month.

(4) "Late wheeze" (LW) is a class with an initial very low incidence, only perceptible from the fourth month, but a slow constant rise through the first 36 months. The age of the first wheezing episode was 19 (12-25) months.

The probability distribution of the four classes was $65.4 \%$ NIW, $18.3 \% \mathrm{TW}, 6.6 \% \mathrm{PW}$, and $9.7 \% \mathrm{LW}$, whereas the modal

Table 2. Covariate differences between classes

\begin{tabular}{|c|c|c|c|c|c|}
\hline & \multicolumn{4}{|l|}{ Modal classification } & \multirow[t]{2}{*}{ p Value } \\
\hline & $\begin{array}{l}\text { Never/infrequent } \\
\text { wheeze }\end{array}$ & $\begin{array}{l}\text { Transient } \\
\text { wheeze }\end{array}$ & $\begin{array}{l}\text { Persistent } \\
\text { wheeze }\end{array}$ & $\begin{array}{l}\text { Late } \\
\text { wheeze }\end{array}$ & \\
\hline Male sex (\%) & 48.6 & 60.1 & 64.1 & 51.6 & $<0.001^{a}$ \\
\hline Season of birth & & & & & $0.518^{\mathrm{a}}$ \\
\hline Winter (\%) & 25.2 & 22.2 & 18.8 & 23.9 & \\
\hline Spring (\%) & 24.6 & 25.1 & 26.5 & 23.5 & \\
\hline Summer (\%) & 25.0 & 28.5 & 28.7 & 26.5 & \\
\hline Autumn (\%) & 25.2 & 24.3 & 26.0 & 26.1 & \\
\hline Birth weight (g), median (IQR) & $3200(2890-3500)$ & $3200(2860-3500)$ & 3230 (2919-3470) & $3170(2860-3470)$ & $0.762^{b}$ \\
\hline $\begin{array}{l}\text { Number of unscheduled visits from } \\
\text { birth to } 36 \text { months, median (IQR) }\end{array}$ & $19(12-29)$ & $28(19-38)$ & $43(31-60)$ & $32(21-46)$ & $<0.001^{b}$ \\
\hline Active asthma at 6 years (\%) & 9.8 & 21.7 & 37.2 & 39.2 & $<0.001^{a}$ \\
\hline Allergic asthma (\% in asthmatics) & 66.3 & 55.6 & 49.1 & 73.5 & $0.014^{a}$ \\
\hline $\begin{array}{l}\text { Wheezing episodes, birth to } 36 \text { months, } \\
\text { median (IQR) }\end{array}$ & $0(0-1)$ & $3(2-3)$ & $6(5-8)$ & $3(2-4)$ & $<0.001^{b}$ \\
\hline $\begin{array}{l}\text { Age at the first episode (months), } \\
\text { median (IQR) }\end{array}$ & $13(7-26)$ & $6(4-9)$ & $6(4-8)$ & $19(22-25)$ & $<0.001^{b}$ \\
\hline $\begin{array}{l}\geq 4 \text { wheezing episodes, birth to } \\
36 \text { months (\%) }\end{array}$ & 0.0 & 23.4 & 98.7 & 36.6 & $<0.001^{\text {a }}$ \\
\hline Wheezing episodes (1st year), median (IQR) & $0(0-0)$ & $2(1-2)$ & $2(1-3)$ & $0(0-1)$ & $<0.001^{\mathrm{b}}$ \\
\hline Wheezing episodes (2nd year), median (IQR) & $0(0-0)$ & $1(0-1)$ & $3(2-3)$ & $1(0-2)$ & $<0.001^{b}$ \\
\hline Wheezing episodes (3rd year), median (IQR) & $0(0-0)$ & $0(0-1)$ & $1(1-2)$ & $2(1-3)$ & $<0.001^{b}$ \\
\hline
\end{tabular}




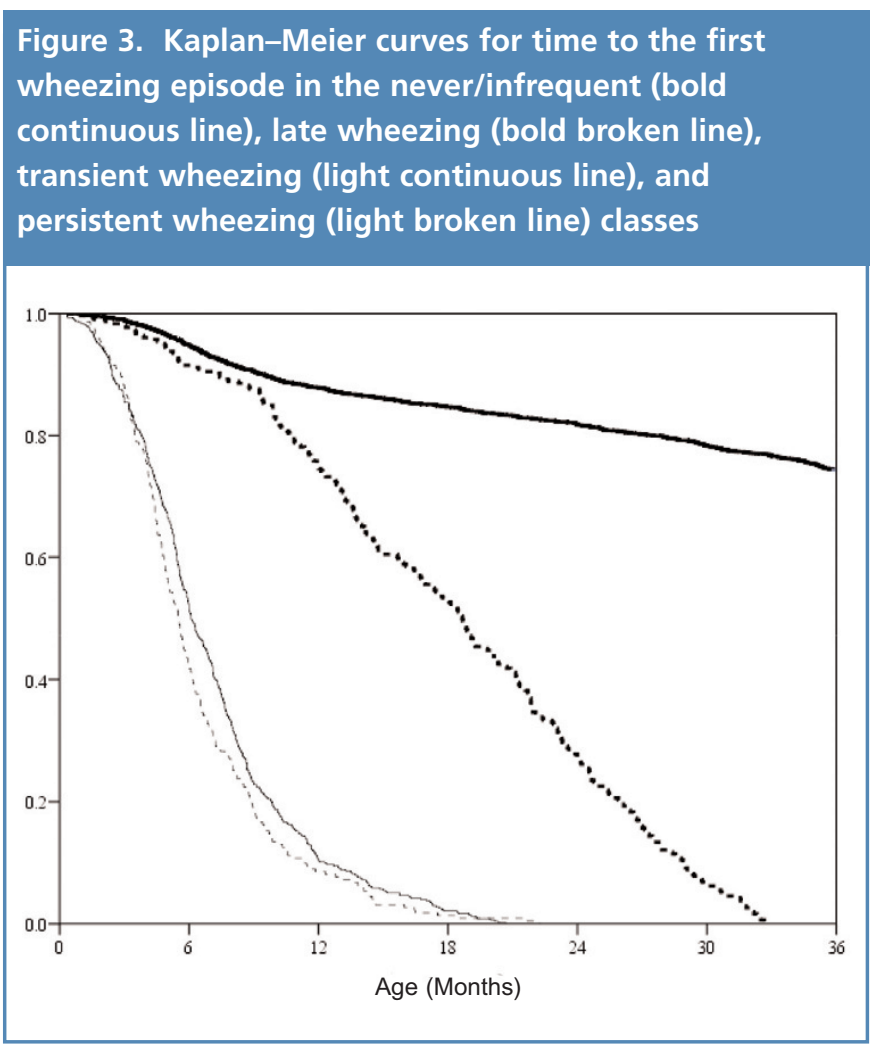

classification allocated $73.2 \%$ of the children to the NIW class, $12.7 \%$ to the TW class, $6.0 \%$ to the PW class, and $8.2 \%$ to the LW class. Therefore, the modal classification incorporates a $15.5 \%$ error rate due to both overestimation in the NIW class and underestimation in the TW class.

The four classes were different regarding some covariates (Table 2). Figure 3 demonstrates the Kaplan-Meier curves for time to the first wheezing episode. The curves for TW and PW classes almost superimpose. The NIW and LW classes initially have close survival curves but, from the ninth month, they progressively diverge.

\section{Prediction of asthma}

Active asthma at six years was more frequent in the TW, PW, and LW classes than in the NIW class. In the NIW and LW classes, asthma at six years was allergic in a higher proportion than in the other two classes. As a whole, 267 of the 573 children with asthma (46.6\%) were classified in the NIW class, $103(18.0 \%)$ in the TEW class, 83 (14.5\%) in the PEW class, and 120 (20.9\%) in the LW class. Prediction of asthma on the basis of the modal classification had a very low sensitivity and a weak predictive performance (Table 3).

\section{Discussion}

\section{Main findings}

Wheezing in the first 36 months can be classified into four discrete phenotypes according to temporal patterns: a never/infrequent phenotype, two early-onset phenotypes that differ in persistence of symptoms but not in the age of onset, and a late-onset phenotype that emerges around the fourth month and slowly becomes the predominant type. The risk of active asthma at six years of age is different among these phenotypes, but the classification has a weak predictive ability for asthma.

\section{Limitations and strengths of this study}

The limitations of the study are due to its historical nature. A first limitation is the risk of unrecorded episodes that can lead to an underestimation of the incidence rate and can also cause imprecision in the definition of the classes. Part of the error in the modal classification could be due to unrecorded episodes - for example, most errors are apparently attributable to a misclassification of children into the NIW class instead of the TW class. However, the number of unrecorded episodes was probably low as the cumulative incidence $(4,676$ episodes in 3,739 children, i.e. 1.25 per child) is even higher than the reported incidence of wheezing in the Copenhagen Prospective Study on Asthma in Childhood, ${ }^{14}$ a highrisk prospective cohort study that identified every wheezing episode in the first three years (290 episodes in 313 children, i.e. 0.93 per child).

A second limitation is the absence of data that were not gathered because they were absent or incomplete in most of the clinical records, and their use might pose a high risk of bias. For instance, allergy tests were seldom performed in non-asthmatic children, so this information is lacking. There is also a lack of information about family history, environmental exposures, and clinical features.

This study also has significant strengths. Data were prospectively

Table 3. Performance of the modal classification in the prediction of active asthma at six years compared with the never/infrequent class

\begin{tabular}{|c|c|c|c|}
\hline Measure & Transient wheeze & Persistent wheeze & Late wheeze \\
\hline Sensitivity (\%) & 27.8 (23.5 to 32.6$)$ & 23.7 (19.6 to 28.4$)$ & 31.0 (26.6 to 35.8$)$ \\
\hline Specificity (\%) & 86.9 (85.6 to 88.1) & 94.6 (93.7 to 95.4$)$ & 93.0 (92.0 to 93.9$)$ \\
\hline Positive predictive value (\%)* & 21.7 (18.3 to 25.7$)$ & 37.2 (31.1 to 43.7) & 39.2 (33.9 to 44.8$)$ \\
\hline Odds ratio & 2.57 (2.00 to 3.30$)$ & $5.48(4.06$ to 7.40$)$ & 5.97 (4.59 to 7.75$)$ \\
\hline $\mathrm{LR}(+)$ & 2.13 (1.76 to 2.58$)$ & 4.42 (3.45 to 5.66$)$ & $4.43(3.61$ to 5.42$)$ \\
\hline$L R(-)$ & 0.83 (0.77 to 0.89$)$ & $0.81(0.75$ to 0.86$)$ & $0.74(0.69$ to 0.80$)$ \\
\hline Brier $_{\text {scaled }}$ & 1.77 & 5.04 & 7.07 \\
\hline
\end{tabular}


recorded and wheeze was confirmed by a physician, thus avoiding the bias posed by data retrospectively obtained from parents' responses to questionnaires." We also established a criterion to separate each episode from the next, avoiding a false multiplication of episodes. The date of each episode was exactly established, allowing for a high-resolution analysis of incidence that has only been done previously in a small selected cohort. ${ }^{14}$ Furthermore, the sample size is relatively large and the rate of losses is small compared with those in other cohort studies.

\section{Interpretation of findings in relation to previously published work}

The four depicted classes are phenotypes characterised by frequency and temporal trajectories. More information is needed before they can be seen as endotypes defined by a distinct pathophysiological mechanism. ${ }^{15}$ A correspondence can be drawn between these classes and those in the ALSPAC study. ${ }^{8}$ The "never/infrequent wheeze", "transient early wheeze", and "persistent wheeze" phenotypes in ALSPAC have their counterparts in the NIW, TW, and PW classes in the SLAM. However, an "intermediate-onset wheeze", with wheezing episodes starting at 18 months, had a much lower frequency in the ALSPAC study (2.7\%) than the LW class in the SLAM study (9.7\%), perhaps because part of the "lateonset wheeze" phenotype of the ALSPAC study was also included in our LW class. Equally, the "prolonged early wheeze" phenotype could be shared between the PW and LW classes. The main difference between the ALSPAC and SLAM studies is that the SLAM study, by using incidence data, has been able to back-track the onset of the "intermediate phenotype" or LW class to the first year.

Regarding very early wheeze, there are two classes both starting at a median age of six months when bronchiolitis is probably the most common diagnosis these episodes get. One of them is transient while the other exhibits a heavy recurrence and a higher risk of asthma symptoms at six years. The differences between nonrecurrent bronchiolitis and bronchiolitis with heavy recurrent postbronchiolitis wheezing are unclear. The type of virus involved in the first infection, ${ }^{16}$ bacterial colonisation of the airways, ${ }^{17}$ and characteristics of the immune response ${ }^{18}$ have all been proposed as causes whereas atopy, effect of pharmacological treatments, and epidemiological characteristics seem not to play a significant role in this setting. ${ }^{10,19-22}$ We did not find any clue that could help in differentiating these two phenotypes.

Prediction of asthma at an early age remains difficult and our results do not improve on previous efforts. Although most of the children with active asthma at six years had wheeze in the first 36 months, $70.2 \%$ of them had less than four episodes in that period and $46.6 \%$ were classified in the NIW class - that is, many children with asthma had a limited clinical expression in the first three years. In some studies up to two-thirds of the children with asthma do not have asthma symptoms in their early years, ${ }^{23}$ and therefore they cannot receive an early diagnosis as any predictive index would have a low sensitivity.

Although the wheezing classes depicted in this study entail an increased risk of asthma compared with a never/infrequent wheeze class, the predictive performance of that classification is poor because of low sensitivity. The most credited procedure to recognise infants at risk of asthma is a modified asthma predictive index (mAPI) which identifies young children who respond to antiinflammatory asthma treatment. This has been proven in studies in which children with a positive mAPI had a mean age of three years. ${ }^{24,25}$ The first criterion for mAPI is the occurrence of four or more wheezing episodes, and in the SLAM cohort the fourth wheezing episode took place at a median (IQR) age of 21 (15-28) months. Therefore, it seems difficult to identify very young children at risk for asthma on the basis of a positive mAPI.

Reduced lung function and increased airway responsiveness since birth have been found in both virus-related wheezing in the first year and asthma in school years, 26,27 so genetic or prenatally acquired airflow limitation could explain the association often detected between these diseases. However, the LW class does not exhibit an incidence peak in the first year, suggesting that congenital airflow limitation is not an important feature of this phenotype which seems to follow the previously described development of allergic sensitisation. ${ }^{28}$

\section{Implications for future research, policy and practice}

This work suggests that the main issues for future research should be the causes underlying the different prognoses for transient and persistent early-onset wheezing and whether atopic predisposition or early allergen exposures drive the surge of late wheezing.

\section{Conclusions}

This work clarifies the spectrum of wheezing-related diseases found in young children and, for the first time, describes the incidence patterns of each phenotype. In clinical practice, two conclusions can be drawn. First, transient and persistent wheezing in the young infant have an identical early onset, so it is difficult to give a prognosis in children with wheezing starting in the first year. Second, as a child grows, a late-onset phenotype becomes the most common type of wheezing, and this phenotype has an increased risk of persistent allergic asthma.

\section{Handling editor Björn Ställberg Statistical review Gopal Netuveli}

Conflicts of interest The authors declare that they have no conflicts of interest in relation to this article.

Contributorship ACG and IMG conceived the study; ACG drafted the study protocol, which was then discussed by all the authors; IMG supervised the field work; all authors (except ACG) contributed to the data; ACG performed the analyses and wrote the manuscript draft; all authors contributed to and approved the final text.

Funding This study was funded by the Fundación Ernesto Sánchez Villares (project 2011/03).

\section{References}

1. Brand PLP, Baraldi E, Bisgaard H, et al. ERS Task Force. Definition, assessment and treatment of wheezing disorders in preschool children: an evidence-based approach. Eur Respir J 2008;32:1096-110. http://dx.doi.org/10.1183/09031936.00002108

2. Mansbach JM, Espinola JA, Macias CG, Ruhlen ME, Sullivan AF, Camargo CA. Variability in the diagnostic labeling of nonbacterial lower respiratory tract infections: a multicenter study of children who presented to the emergency department. Pediatrics 2009;123:e573-81. http://dx.doi.org/10.1542/peds.2008-1675

3. Martinez FD, Wright AL, Taussig LM, Holberg CJ, Halonen M, Morgan WJ. Asthma and wheezing in the first six years of life. N Engl J Med 1995;332:133-8. http://dx.doi.org/10.1056/NEJM199501193320301 
4. Bergmann RL, Bergmann KE, Lau-Schadensdorf S, et al. Atopic diseases in infancy. The German multi-center atopy study (MAS-90). Pediatr Allergy Immunol 1994;5(6 Suppl):19-25.

5. Kurukulaaratchy RJ, Fenn MH, Waterhouse LM, Matthews SM, Holgate ST, Arshad $\mathrm{SH}$. Characterization of wheezing phenotypes in the first 10 years of life. Clin Exp Allergy 2003;33:573-8. http://dx.doi.org/10.1046/j.1365-2222.2003.01657.x

6. Hagenaars JA, McCutcheon AL, eds. Applied latent class analysis. Cambridge: Cambridge University Press, 2002. http://dx.doi.org/10.1017/CBO9780511499531

7. Spycher BD, Silverman M, Brooke AM, Minder CE, Kuehni CE. Distinguishing phenotypes of childhood wheeze and cough using latent class analysis. Eur Respir J 2008;31:974-81. http://dx.doi.org/10.1183/09031936.00153507

8. Henderson J, Granell R, Heron J, et al. Associations of wheezing phenotypes in the first 6 years of life with atopy, lung function and airway responsiveness in midchildhood. Thorax 2008;63:974-80. http://dx.doi.org/10.1136/thx.2007.093187

9. Savenije $O E$, Granell R, Caudri D, et al. Comparison of childhood wheezing phenotypes in two birth cohorts: ALSPAC and PIAMA. J Allergy Clin Immunol 2011;127:1505-12. http://dx.doi.org/10.1016/j.jaci.2011.02.002

10. Herr M, Just J, Nikasinovic L, et al. Risk factors and characteristics of respiratory and allergic phenotypes in early childhood. J Allergy Clin Immunol 2012;130:389-96. http://dx.doi.org/10.1016/j.jaci.2012.05.054

11. Mohangoo AD, de Koning HJ, Hafkamp-de Groen $\mathrm{E}$, et al. A comparison of parentreported wheezing or shortness of breath among infants as assessed by questionnaire and physician-interview: The Generation R Study. Pediatr Pulmonol 2010;45:500-07.

12. Kim HJ, Fay MP, Feuer EJ, Midthune DN. Permutation tests for joinpoint regression with applications to cancer rates. Stat Med 2000;19:335-51 (correction: Stat Med 2001;20:655). http://dx.doi.org/10.1002/sim.811

13. Steyerberg EW, Vickers AJ, Cook NR, et al. Assessing the performance of prediction models. A framework for traditional and novel measures. Epidemiology 2010;21:128-38. http://dx.doi.org/10.1097/EDE.0b013e3181c30fb2

14. Skytt N, Bønnelykke K, Bisgaard H. "To wheeze or not to wheeze"': that is not the question. J Allergy Clin Immunol 2012;130:403-07. http://dx.doi.org/10.1016/j.jaci.2012.04.043

15. Lötvall J, Akdis CA, Bacharier LB, et al. Asthma endotypes: a new approach to classification of disease entities within the asthma syndrome. J Allergy Clin Immunol 2011;127:355-60. http://dx.doi.org/10.1016/j.jaci.2010.11.037

16. Midulla F, Pierangeli $A$, Cangiano $G$, et al. Rhinovirus bronchiolitis and recurrent wheezing: 1-year follow-up. Eur Respir J 2012;39:396-402. http://dx.doi.org/10.1183/09031936.00188210

17. Jartti $T$, Kuneinen $S$, Lehtinen $P$, et al. Nasopharyngeal bacterial colonization during the first wheezing episode is associated with longer duration of hospitalization and higher risk of relapse in young children. Eur J Clin Microbiol Infect Dis 2011; 30:233-41. http://dx.doi.org/10.1007/s10096-010-1075-z

18. Ermers MJ, Janssen R, Onland-Moret NC, et al. IL10 family member genes IL19 and IL20 are associated with recurrent wheeze after respiratory syncytial virus bronchiolitis. Pediatr Res 2011;70:518-23. http://dx.doi.org/10.1203/PDR.0b013e31822f5863

19. Bisgaard H, Flores-Nuñez A, Goh A, et al. Study of montelukast for the treatment of respiratory symptoms of post-respiratory syncytial virus bronchiolitis in children. Am J Respir Crit Care Med 2008;178:854-60. http://dx.doi.org/10.1164/rccm.200706-9100C

20. Ermers MJJ, Rovers MM, van Woensel JBM, Kimpen JLL, Bont $\sqcup$. The effects of high dose inhaled corticosteroids on wheeze in infants after respiratory syncytial virus infection: randomised double blind placebo controlled trial. BMJ 2009;338:b897. http://dx.doi.org/10.1136/bmj.b897

21. Bisgaard H, Hermansen MN, Loland L, Halkjaer LB, Buchvald F. Intermittent inhaled corticosteroids in infants with episodic wheezing. N Engl J Med 2006;354:19982005. http://dx.doi.org/10.1056/NEJMoa054692

22. Granell R, Sterne JAC, Henderson J. Associations of different phenotypes of wheezing illness in early childhood with environmental variables implicated in the aetiology of asthma. PLOS ONE 2012;7:e48359. http://dx.doi.org/10.1371/journal.pone.00483599

23. Matricardi PM, Illi S, Grüber C, et al. Wheezing in childhood: incidence, longitudinal patterns and factors predicting persistence. Eur Respir J 2008;32:585-92. http://dx.doi.org/10.1183/09031936.00066307

24. Guilbert TW, Morgan WJ, Zeiger RS, et al. Long-term inhaled corticosteroids in preschool children at high risk for asthma. N Engl J Med 2006;354:1985-97 http://dx.doi.org/10.1056/NEJMoa051378.

25. Bacharier LB, Phillips MS, Zeiger RS, et al. Episodic use of an inhaled corticosteroid or leukotriene receptor antagonist in preschool children with moderate-to-severe intermittent wheezing. J Allergy Clin Immunol 2008;122:1127-35. http://dx.doi.org/10.1016/j.jaci.2008.09.029

26. Bisgaard $H$, Jensen SM, Bønnelykke K. Interaction between asthma and lung function growth in early life. Am J Respir Crit Care Med 2012;185:1183-9. http://dx.doi.org/10.1164/rccm.201110-19220C

27. van der Zalm MM, Uiterwaal CSPM, Wilbrink B, Koopman M, Verheij TJM, Van der Ent CK. The influence of neonatal lung function on rhinovirus-associated wheeze. Am J Respir Crit Care Med 2011;183:262-7. http://dx.doi.org/10.1164/rccm.200905-07160C

28. Kulig M, Bergmann $R$, Klettke $U$, et al. Natural course of sensitization to food and inhalant allergens during the first 6 years of life. J Allergy Clin Immunol 1999;103:1173-9. http://dx.doi.org/10.1016/S0091-6749(99)70195-8

\section{Available online at http://www.thepcrj.org}




\section{Appendix 1. Causes of exclusion}

\begin{tabular}{|c|c|}
\hline Causes of exclusion: & $\begin{array}{c}\text { № } \\
\text { excluded }\end{array}$ \\
\hline Tuberculosis. & 3 \\
\hline Bronchopulmonary dysplasia/chronic neonatal lung disease. & 2 \\
\hline$\alpha$-1-antitrypsin deficiency. & 1 \\
\hline Foreign body aspiration. & 1 \\
\hline $\begin{array}{l}\text { Pulmonary congenital anomalies: pulmonary secuestration, vascular rings, bronchial stenosis, cystic } \\
\text { adenomatoid malformation, bronchogenic cysts, congenital pulmonary lymphangiectasia, congenital } \\
\text { lobar amphysema. }\end{array}$ & 2 \\
\hline $\begin{array}{l}\text { Congenital heart disease, except mild non-complicated lesions as small patent ductus arteriosus, } \\
\text { auricular septal defects and ventricular septal defects. }\end{array}$ & 18 \\
\hline $\begin{array}{l}\text { Neuromuscular disorders and cerebral palsy with Gross Motor Function Classification System } \geq 4 \\
\text { (children cannot sit on their own). }\end{array}$ & 7 \\
\hline Chronic aspiration syndrome. & 1 \\
\hline $\begin{array}{l}\text { Interstitial lung diseases as pulmonary alveolar proteinosis, sarcoidosis, surfactant dysfunction disorders, } \\
\text { hipersensitivity neumonitis, eosinophilic pneumonia, neuroendocrine cell hyperplasia of infancy, } \\
\text { desquamative interstitial pneumonitis and others. }\end{array}$ & 1 \\
\hline \multicolumn{2}{|l|}{ Other prespecified exclusion criteria not met for any children: } \\
\hline \multicolumn{2}{|l|}{ Cystic fibrosis. } \\
\hline \multicolumn{2}{|l|}{ Pulmonary hemosiderosis. } \\
\hline \multicolumn{2}{|l|}{ Sickle cell disease. } \\
\hline \multicolumn{2}{|l|}{ Bronchiectasis. } \\
\hline \multicolumn{2}{|l|}{ Bronchiolitis obliterans, bronchitis follicular. } \\
\hline \multicolumn{2}{|l|}{ Primary ciliary dyskinesia/Kartagener syndrome. } \\
\hline \multicolumn{2}{|l|}{ Immunodeficiency, except selective IgA deficiency and IgG subclass deficiencies. } \\
\hline \multicolumn{2}{|l|}{ Severe thoracic deformities. } \\
\hline Primary or metastatic lung neoplasms. & \\
\hline
\end{tabular}


Appendix 2. Latent-class analysis, best model selection

\begin{tabular}{|c|c|c|c|c|c|c|c|}
\hline $\begin{array}{c}\text { Number } \\
\text { of clusters }\end{array}$ & LL & BIC(LL) & Npar & $L^{2}$ & df & $\begin{array}{c}\text { p-value } \\
\text { (bootstrap L }{ }^{2} \text { test)) }\end{array}$ & $\begin{array}{c}\text { Percent errors in } \\
\text { modal classification }\end{array}$ \\
\hline 1 & -13535.753 & 27170.225 & 12 & 4603.694 & 3727 & $<0.001$ & 0 \\
\hline 2 & -12242.737 & 24691.139 & 25 & 2017.662 & 3714 & $<0.001$ & 6.64 \\
\hline 3 & -12119.495 & 24551.599 & 38 & 1771.177 & 3701 & $<0.001$ & 15.46 \\
\hline 4 & -12043.704 & 24506.962 & 51 & 1619.595 & 3688 & 0.150 & 14.90 \\
\hline 5 & -12022.328 & 24571.156 & 64 & 1576.843 & 3675 & 0.250 & 19.30 \\
\hline 6 & -11995.222 & 24623.890 & 77 & 1522.631 & 3662 & 0.314 & 19.76 \\
\hline 7 & -11980.017 & 24700.425 & 90 & 1492.221 & 3649 & 0.250 & \\
\hline
\end{tabular}

LL: Log-likelihood; BIC(LL): Bayesian information criterion based on LL; Npar: number of parameters; $\mathrm{L}^{2}$ : L-squared, likelihood ratio goodness-of-fit; df: degrees of freedom. 
Appendix 3. Diagnostic of joinpoint regression models

\begin{tabular}{|l|c|c|c|c|c|}
\hline \multirow{2}{*}{ Model } & \multirow{2}{*}{$\mathrm{R}^{2}$} & \multicolumn{2}{|c|}{$\begin{array}{c}\text { Durbin-Watson test for } \\
\text { autocorrelation* }\end{array}$} & $\begin{array}{c}\text { Shapiro-Wilk test of } \\
\text { standardized residuals for } \\
\text { normality assumption } \\
\text { statistic and significance } \\
\text { level)** }\end{array}$ & $\begin{array}{c}\text { Breusch-Pagan test for } \\
\text { homoscedasticity } \\
\text { assumption } \\
\text { (significance level)*** }\end{array}$ \\
\cline { 2 - 5 } & 0.920 & 2.08750 & 1.91250 & $0.979(\mathrm{p}=0.705)$ & $\mathrm{p}=0.160$ \\
\hline IR TW & 0.783 & 1.77444 & 2.22556 & $0.980(\mathrm{p}=0.746)$ & $\mathrm{p}=0.732$ \\
\hline IR PW & 0.871 & 1.67537 & 2.32463 & $0.979(\mathrm{p}=0.707)$ & $\mathrm{P}=0.069$ \\
\hline IR NIW & 0.906 & 1.77245 & 2.22755 & $0.892(\mathrm{p}=0.002)$ & $\mathrm{p}=0.210$ \\
\hline
\end{tabular}

NIW: never/infrequent wheeze class; TW: transient wheeze class; PW: persistent wheeze class; LW: late wheeze class; $\mathrm{R}^{2}$ : coefficient of determination.

*For a model with intercept, only one predictive variable and 36 point cases, autocorrelation (positive or negative) can be excluded at a significance level of 0.1 if both $d$-value and (4-d) value are $>1.31499^{(1)}$. ** If $p>0.05$, a normal distribution of residuals can be assumed.

*** If $p>0.05$, homoscedasticity of residuals can be assumed.

The four joinpoint regression models fulfilled all the assumptions, except the normality assumption in the NIW model. Log transformation did not improve the fit of this model to a normal distribution.

(1) Savin NE, White KJ. The Durbin-Watson test for serial correlation with extreme sample sizes or many regressors. Econometrica $1977 ; 45: 1989-96$ 
Appendix 4. Flow diagram

Six year-old children in the population covered by the participating primary health care practices

4765
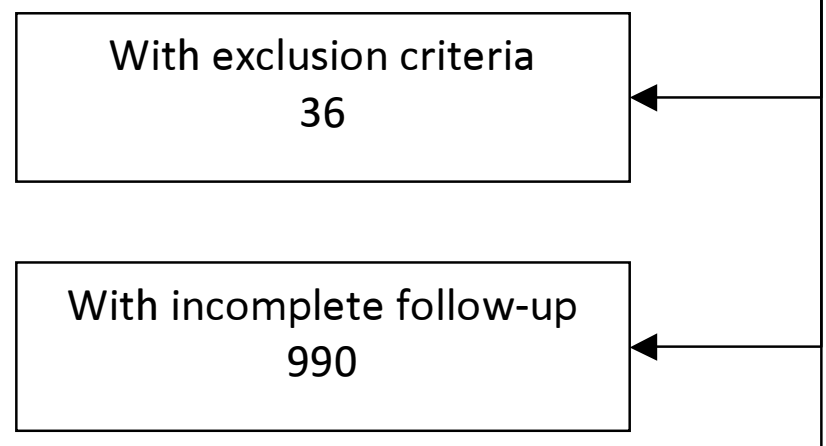

Children with complete follow-up

3739

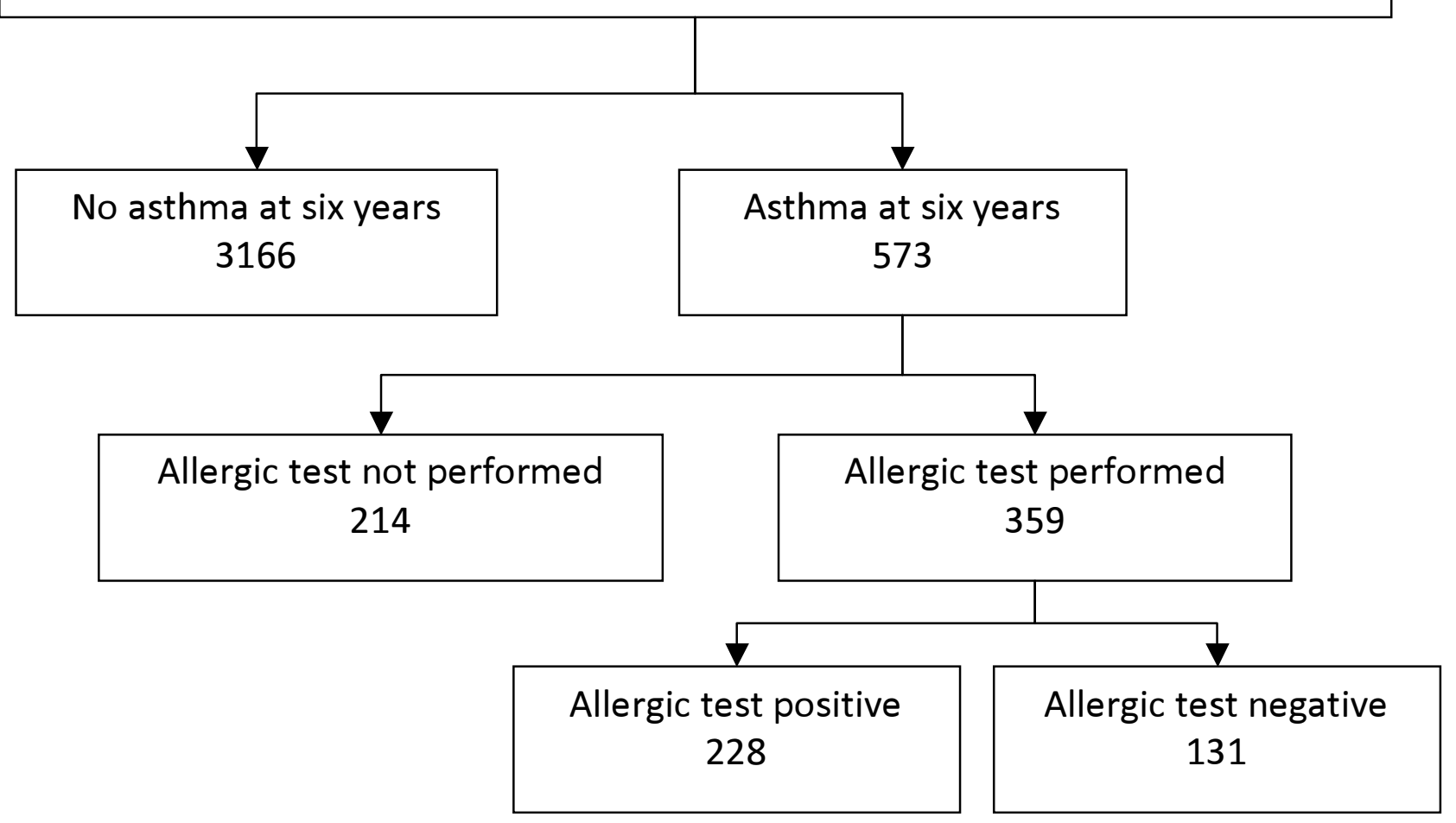

